IZA DP No. 8370

Same-Occupation Spouses:

Preferences and Search Costs

Hani Mansour

Terra McKinnish

August 2014

Forschungsinstitut zur Zukunft der Arbeit Institute for the Study of Labor 


\title{
Same-Occupation Spouses: Preferences and Search Costs
}

\author{
Hani Mansour \\ University of Colorado Denver \\ and IZA \\ Terra McKinnish \\ University of Colorado Boulder
}
Discussion Paper No. 8370
August 2014

IZA
P.O. Box 7240
53072 Bonn
Germany

Phone: +49-228-3894-0

Fax: +49-228-3894-180

E-mail: iza@iza.org

\begin{abstract}
Any opinions expressed here are those of the author(s) and not those of IZA. Research published in this series may include views on policy, but the institute itself takes no institutional policy positions. The IZA research network is committed to the IZA Guiding Principles of Research Integrity.

The Institute for the Study of Labor (IZA) in Bonn is a local and virtual international research center and a place of communication between science, politics and business. IZA is an independent nonprofit organization supported by Deutsche Post Foundation. The center is associated with the University of Bonn and offers a stimulating research environment through its international network, workshops and conferences, data service, project support, research visits and doctoral program. IZA engages in (i) original and internationally competitive research in all fields of labor economics, (ii) development of policy concepts, and (iii) dissemination of research results and concepts to the interested public.
\end{abstract}

IZA Discussion Papers often represent preliminary work and are circulated to encourage discussion. Citation of such a paper should account for its provisional character. A revised version may be available directly from the author. 
IZA Discussion Paper No. 8370

August 2014

\section{ABSTRACT}

\section{Same-Occupation Spouses: Preferences and Search Costs}

Married individuals match with spouses who share their occupation more frequently than predicted by chance, suggesting either a preference for same-occupation matches or lower search costs within occupation. To distinguish between these explanations, we use a differences-in-differences strategy that compares the difference in wages between sameoccupation husbands and different-occupation husbands across occupations with different percent male workers. Under the preferences mechanism, the difference should be decreasing in percent male. Under the search cost mechanism, the difference should be increasing in percent male. Our results are consistent with the search cost explanation, especially in occupations with greater degree of workplace communication.

JEL Classification: J12, J24

Keywords: marital sorting, occupation, sex ratio, search frictions

Corresponding author:

Hani Mansour

Department of Economics

University of Colorado Denver

Campus Box 181

P.O. Box 173364

Denver, CO 80217-3364

USA

E-mail: hani.mansour@ucdenver.edu

\footnotetext{
* We gratefully acknowledge helpful comments from Chris Bollinger, Murat Iyigun and Rick Mansfield as well as seminar participants at the University of Kentucky and Osaka University.
} 


\section{Introduction}

Married individuals match with spouses who share their occupation more frequently than should happen by chance if marriage markets are large frictionless search markets covering a particular geographic area. Given that the opposite-sex members of one's occupation in most cases comprise a relatively small fraction of the total number of available spouses in the local marriage market, a disproportionate match rate within occupation suggests either a preference for same-occupation matches or that search costs are lower within occupation.

Distinguishing between these two potential explanations has important implications for our understanding of how marriage markets function. Evidence that individuals match within occupation primarily because it is simply easier to meet people of the same occupation would suggest that marriage markets are much more local than typically modeled or described by economists (e.g. Chiappori, Fortin and Lacroix, 2002; Choo and Siow, 2006). This implies that choices about where to work or where to go to school can have important consequences for matching by changing the group of people with whom one interacts most easily.

This paper uses 2008-2011 data from the American Community Survey (ACS) to analyze same-occupation matching among a sample of recently-married couples. We first document that same-occupation matching is strongly related to the sex composition of the occupation. In order to distinguish between a preferences explanation and a search cost explanation, we investigate whether women accept lower-wage husbands if they match within-occupation compared to if they do not, and how this wage gap varies with the sex composition of the occupation.

If women receive marital surplus from same-occupation matches, then we should observe them trading off this spousal characteristic with other desirable husband qualities, such as husband's wage. This trade-off should be particularly stark for women in occupations where men are scarce. Alternatively, if women experience low search costs within occupation, they 
may be willing to accept lower wage same-occupation husbands to avoid paying the higher search costs of outside-occupation search. This trade-off should be particularly stark for women in occupations where men are plentiful. This suggests a differences-in-differences strategy in which we compare the difference in wages between same-occupation husbands and differentoccupation husbands across occupations with different percent male workers. Under the preferences mechanism, the difference should become less negative as percent male increases. Under the search cost mechanism, the difference should be become more negative as percent male increases. Our differences-in-differences results indicate that the difference in wages between same-occupation and different-occupation husbands becomes more negative as percent male in occupation increases. This is consistent with the search costs mechanism.

Additionally, because the search cost mechanism should be most relevant in occupations with sufficient workplace interaction to facilitate search, we extend our differences-indifferences model to a triple-differences model using interactions with an occupation-specific index of workplace communication. When we add interactions with the workplace communication index, we find, as predicted, the results are most consistent with a search cost mechanism when there is a greater degree of workplace communication.

Previous work has pointed out that similarities between husbands and wives in characteristics such as education and race can be generated either by preferences or search frictions (Kalmijn 1998, Nielsen and Svarer, 2009, Hitsch, Hortascsu and Ariely, 2010, Belot and Francesconi, 2013), but there is limited empirical evidence on the relative importance of search frictions. Belot and Francesconi (2013) use British speed-dating data which allows them to analyze the effects of changes in choice set on dating proposals. They find that meeting opportunities play a substantial role in dating choices. Nielsen and Svarer (2009) show using Danish data that about half of marital sorting on education is due to individuals marrying spouses 
who attended the same or nearby educational institutions, suggesting a role for search frictions. Hitsch, Hortascsu and Ariely (2010) use preferences estimates generated from online dating data to predict marriages under the assumption of frictionless search. They underpredict sorting by education and race/ethnicity, suggesting a potential role for search frictions.

Ours is the first paper to consider same-occupation matching, and the first paper to use information on spousal quality to investigate the relative importance of preferences and search frictions in assortative matching.

\section{Same-Occupation Matching}

\section{A. Descriptive Statistics}

Table 1 presents descriptive statistics by occupation on sex composition and sameoccupation matching using 2008-2011 ACS data. Descriptive statistics are reported for 79 occupation categories based on the 2-digit SOC codes. The first two columns report the total number of observations and the percent female using the sample of women and men ages 22-55 who report an occupation for most recent job in the past 5 years. Columns 3 and 4 report the fraction of women and men, respectively, married to a same-occupation spouse. The table is sorted on fraction female in occupation from the least female to the most female occupations.

From the table, it is clear that there is considerable same-occupation matching, and also that same-occupation matching is particularly common for individuals in occupations with a high proportion of workers of the opposite sex. For example, 53\% of married women in the military are married to military husbands, $29 \%$ of female engineers are married to male engineers, and $38 \%$ of male schoolteachers are married to female schoolteachers.

In most cases, the opposite-sex workers in one's occupation only represent a fraction of one's broader marriage market prospects. Therefore, if same-occupation matches are both frequent and responsive to the sex-composition of one's occupation, this suggests that there is 
some marriage market feature that gives advantage to same-occupation matches over differentoccupation matches. ${ }^{1}$

Kalmijn (1998) and Hitsch, Hortascsu and Ariely (2010) have previously pointed out that similarities between husband and wife in characteristics such as education and race can result from preferences or from search frictions. It could be that individuals, all else equal, prefer same-occupation partners. Alternatively, if martial search is costly, the fact that individuals often spend a lot of time in the company of individuals with their same occupation could also generate such sorting.

\section{B. Preferences Explanation}

It could be that individuals prefer same-occupation spouses. For example, it is likely that individuals within the same occupation are more homogenous in their preferences compared to the larger marriage market. If individuals experience greater marital surplus by matching with partners with similar preferences for consumption of leisure, investments in children, and so forth, then a preference for partners for similar tastes would generate a higher rate of matching within occupation

If there were equal numbers of men and women within each occupation, and sameoccupation matches increased marital surplus, then a simple matching model would predict that all individuals would match with same-occupation spouses and then match assortively on quality within occupation. The more realistic case is that there is a sex imbalance in most occupations, some having a surplus of men and some having a surplus of women. In this case, those in excess supply will have to, on average, marry down in order to match within occupation.

\footnotetext{
${ }^{1}$ An additional explanation for within-occupation matching is that married individuals might recruit their partners into their own occupations after matching. For example, in Table 1, it might be that the very few women who report being fishers, hunters or trappers are in that category because their husbands brought them into the occupation, generating a very large within-occupation matched rate for women in that occupation (0.40). This explanation is much less likely to be relevant for married individuals with college degrees, because entrance into an occupation often requires investment in specialized education and training.
} 
The case of two-dimensional matching with sex imbalances is formally modeled in Chiappori, Oreffice and Quintana-Domeque (2010). They apply their model to the case in which non-smokers prefer to match with non-smokers, and there is excess supply of female nonsmokers (because more men smoke than women). They predict that among husbands of equal quality non-smoking wives, non-smoking husbands will on average be less educated than smoking husbands. ${ }^{2}$ In other words, among equal quality non-smoking wives, those who match, as desired, with non-smoking husbands will have to on average take a husband who is less educated.

The case in which workers prefer to match with same-occupation spouses fits nicely into the Chiappori et al. theoretical framework, with the additional beneficial empirical feature that rather than a single category (smoking) with a single sex composition, we are able to compare marital sorting across multiple occupations with very different sex-compositions. This provides an empirical test for a preferences explanation for same-occupation matching. ${ }^{3}$ In occupations in which men are scarce, women will have to on average marry lower quality men in order to match within-occupation. Comparing similar quality women in the same occupation, the average quality of same-occupation husbands should be lower than the average quality of differentoccupation husbands. In occupations in which men are less scarce, this difference between same-occupation husbands and different-occupation husbands should become less negative.

\footnotetext{
${ }^{2}$ Their theoretical model does not include the empirical reality of a negative correlation between smoking and education. Therefore, when implementing this prediction empirically, it is adapted to a prediction that the negative correlation between smoking and education becomes less negative when the sample is restricted to husbands of nonsmoking wives, and even less negative when a control for wife's quality (education) is added to the model. This prediction is confirmed empirically. Our empirical analysis does not suffer from this issue because we are comparing across many occupations with different sex compositions, allowing us to control for average quality in each occupation with fixed-effects, focusing on the interaction of sex-composition and same-occupation matching. ${ }^{3}$ Following Chiappori et al. (2010), it does not matter whether both men and women prefer same-occupation spouses or only one side of the market has this preference. If, for example, women prefer same-occupation matches, then men will, all else equal, also prefer a same-occupation match, because otherwise the woman will have to be compensated for the loss of marital surplus from a different-occupation match.
} 
More generally, this approach fits in with a broader literature in which individuals trade off a specific spousal characteristic with other desirable partner qualities. Chiappori, Oreffice and Quintana-Domeque (forthcoming), for example, estimate the marriage market trade-off between earnings and Body Mass Index. Angrist (2002) studies marriage among $2^{\text {nd }}$ generation immigrants, who often prefer endogamous (within ethnicity) marriages. Using U.S. Census data from 1910-1940, he documents that $2^{\text {nd }}$ generation women obtained higher quality husbands on average when the sex ratio within ethnicity was more favorable. Other studies have also documented that more favorable sex ratios allow individuals to marry higher quality partners (Abramitzky et al., 2011; Charles and Luoh, 2010; Lafortune, 2010).

\section{Search Cost Explanation}

An alternative explanation for same-occupation matches is based on search costs. To consider the implications of search costs, we first consider the simplest case in which there is no difference in search costs between within-occupation search and outside-occupation search. ${ }^{4}$ In the absence of preferences for same-occupation matches, we would expect there to be no difference in spousal quality when comparing same-occupation spouses and different-occupation spouses.

Suppose some individuals face lower search costs than others, but still, for any given individual, there is no difference in search cost between within-occupation search and outsideoccupation search. Individuals who face lower search costs should have higher reservation values and should match with higher quality spouses, but there is still no predicted difference in spousal quality between same-occupation matches and different-occupation matches.

\footnotetext{
${ }^{4}$ There is a substantial literature on models of marriage markets with search frictions. Unlike the perfect assortative matching predicted in frictionless markets, in the presence of search frictions markets will develop a class structure in which individuals match with one of a range of acceptable partners rather than their ideal partner (Burdette and Coles, 1997; Bloch and Ryder, 2000; Smith, 2006; Jacquet and Tan, 2007). These models, however, do not allow search costs to vary across different types of potential partners or across different marriage markets.
} 
Now consider a model in which individuals have two search pools with potentially different search costs: a within-occupation pool and an outside-occupation pool. For a given search pool with search cost $c$ and a distribution of spousal quality $\mathrm{F}(q)$, an individual searching in the pool will have a reservation quality $w$ as described by:

$$
\int_{w}^{\bar{q}}(q-w) d F(q)=c
$$

The reservation quality, $w$, is therefore the expected value of searching in the pool. Under optimal sequential search, individuals search in the pool with the highest expected value, $w$, and then search until they find a match with $q>w$ (Weitzman, 1979). It is clear that $\partial w / \partial c<0$, so that all else equal, the returns to search will be highest in the pool with the lowest search cost.

An individual in an occupation with a very favorable sex ratio faces lower within occupation search costs relative to outside occupation. ${ }^{5}$ In this case, the individual should only search outside their occupation if the expected return from outside occupation dominates the expected within occupation return , that is if $\mathrm{F}(q)$ is shifted to the right in the outside-occupation pool.

This implies that as the percent male in an occupation increases, lowering $\mathrm{c}$ in the withinoccupation pool, the fraction of women who match within-occupation should increase. The remaining women who choose to pay the higher search cost and match outside-occupation should be women who expect particularly high realizations of husband quality from search in the outside-occupation pool. Therefore, where the sex ratio is very favorable, we should see that the women who match outside-occupation have husbands with higher wages than those who

\footnotetext{
${ }^{5}$ In this discussion we consider changes in sex-mix (c) holding constant the distribution of quality in the occupation. Clearly, empirically there is a relationship between sex-mix of an occupation and the wage distribution in the occupation. Our empirical analysis, however, will use occupation fixed-effects as well as interactions with occupation wage characteristics to control for this empirical relationship.
} 
matched within-occupation. ${ }^{6}$ Put another way, when percent male in occupation is high, women may accept lower quality husbands within-occupation than they could obtain outside-occupation in order to avoid the greater search costs of outside-occupation search. ${ }^{7}$

Both the preferences and the search cost explanations predict that there will be cases where, comparing across women of the same occupation, same-occupation husbands have lower average quality compared to different-occupation husbands. The difference between the two mechanisms is where this gap will be larger. With the preferences mechanism, the negative gap should be greatest where men are scarce, and women have to sacrifice more on quality in order to match with a same-occupation husband. With the search cost mechanism, the negative gap should be greatest where men are plentiful, generating the largest difference in search costs between within-occupation and outside-occupation search.

\section{Matching and Occupation Sex Composition}

In our empirical analysis, we first formally document the relationship between sameoccupation matching and occupation sex-composition that is suggested in Table 1 . We then test for the differences in spousal quality predicted by the preferences and search cost explanations.

\section{A. Occupation Characteristics}

Using the 2008-2011 ACS sample used in columns 1 and 2 of Table 1, percent female is calculated at the 3-digit SOC level, producing sex-composition measures for 333 occupations.

\footnotetext{
${ }^{6}$ A similar empirical prediction is generated by the two-sided search market with frictions in Moen (1997). In his model, submarkets vary by wage and search costs (workers per vacancy). Submarkets with higher wages attract more workers per vacancy and therefore have greater search costs. A comparison of identical workers who matched in different submarkets will find that the worker who matched in the market with greater search costs is receiving a higher wage.

${ }^{7}$ This may at first seem counter-intuitive, because we expect lower search costs to generate matches with higher quality husbands. But in this case, we are not comparing women across occupations facing different search costs. If we were, then we would predict that women in occupations with lower search costs should on average match with higher quality husbands. Instead, we are comparing women in the same occupation who match either with sameoccupation husbands or different occupation husbands.
} 
Using this same sample and set of occupations, a measure of occupation size is calculated separately by college education and by sex. For occupation $j$ and college status $k(=0 / 1)$ : MaleShare $_{j k}=$ \# men with college status $k$ and occupation $j / \#$ men with college status $k$, and FemaleShare $_{j k}=$ \# women with college status $k$ and occupation $j / \#$ women with college status $k$.

It is important to distinguish between, for example, the \%Female and FemaleShare measures for a particular occupation. \%Female measures the fraction of workers within that occupation that are female and is unrelated to occupation size. FemaleShare measures the fraction of female workers, of a particular college status, that work in that occupation. The MaleShare and FemaleShare variables therefore measure which occupations are large or small employers of a particular sex and education group.

Finally, a regional concentration measure is calculated, defined as the fraction of men or women in the region employed in an occupation minus the mean fraction for that occupation across all regions.

\section{B. Analysis Sample}

Data from the 2008-2011 American Community Survey (ACS) are used because year of marriage is reported in these years. This allows the analysis to be conducted on a sample of recently-married couples. This has two benefits. First, an individual's current reported occupation should be similar to his/her occupation at the time he/she matched with a spouse. Second, we reduce sample selection bias that could occur if same-occupation couples divorce at different rates than those who are not matched on occupation.

The analysis sample includes married couples who a) are in their first marriage, b) have been married for 5 years or less, c) are ages 22-45, and d) the wife is native-born non-Hispanic white. This restricts the sample to women who face more homogenous marriage markets. 
Using the 2-digit SOC codes used in Table 1, 9.2\% of couples in our analysis sample are matched on occupation. Using the 333 3-digit categories that we use in our regression analysis, $6.1 \%$ of couples share the same occupation.

\section{Sex Composition and Matching}

While prior work has documented the fact that spouses match on occupational status (Hout 1982; Kalmijn 1994), this is the first work to explore matching within specific, detailed occupations and the role of sex-composition.

The following specification estimates the relationship between same-occupation matching and sex composition of the husband's and wife's occupations:

$$
\begin{aligned}
\text { Same_Occ }_{i j k}= & \beta_{0}+\beta_{1} \% \text { Male }_{j}+\beta_{2} \% \text { Female }_{k}+\text { Occ_Char }_{j k} \beta_{3}+X_{i} \beta_{4} \\
& +\sum_{s=1}^{S} \delta_{s} * \text { State }_{i}+\sum_{s=1}^{S} \gamma_{s} * \text { State }_{i} * \text { Urban }_{i}+\varepsilon_{i j k}
\end{aligned}
$$

For couple $i$ with wife's occupation $j$ and husband's occupation $k$, Same_Occ is an indicator variable equaling one if the husband and wife have the same occupation. $\% M_{a l e}$ is percent male in wife's occupation and \%Female ${ }_{k}$ is percent female in husband's occupation. Occ_Char contains the other occupation characteristics for husband's and wife's occupations: MaleShare for wife's occupation (and college status), FemaleShare for husband's occupation (and college status), and the regional concentration measures for husband's and wife's occupations. The vector $X$ contains couple characteristics including husband's and wife's age and age-squared, husband's and wife's education (indicators for high school degree, college degree, and advanced degree), an indicator for whether husband and wife have the same educational attainment (using the categories already described), husband's race/ethnicity (indicators for non-Hispanic white, non-Hispanic black, Hispanic), and the wife's age of marriage and its square. The control for whether the husband and wife share the same level of education separates out matching on occupation, conditional on education, from the well-documented educational sorting in the 
marriage market. The model also contains state fixed-effects and a separate vector of statefixed-effects for urban residents. Standard errors are two-way clustered by wife's and husband's occupation (Cameron and Miller, 2011).

D. Results

Table 2 reports the results from equation (1). Column 1 reports the results for the full sample. For both husband and wife, a higher fraction of opposite-sex workers in their occupation increases the probability they match within occupation, although the relationship is stronger for percent male in wife's occupation. In columns 2 and 3, the sample is split by wife's education. For the college-educated sample, the coefficients on the sex composition variables are similar in magnitude to those for the full sample, but the coefficient on percent female in husband's occupation is now statistically insignificant. For the sample of wives with less than a college education, the coefficients on sex composition in wife's occupation and in husband's occupation are much more symmetric and both statistically significant. Overall, the results confirm a positive relationship between fraction of workers of the opposite sex in own occupation and matching with a same-occupation spouse.

\section{Preferences versus Search Costs}

The preferences and search costs explanations for same-occupation matching have different implications for spousal quality. Our analysis focuses on husband's quality, specifically husband's wage. The empirical literature has established that husband's wage is an important determinant of marital surplus for the wife. In contrast, wife’s wage is more problematic as a measure of wife's quality, both because of evidence that the labor market effort of wives is endogenous to partner characteristics, and also because men place less weight on women’s potential earnings in mate selection (Fisman et al, 2006; Oreffice and QuintaDomeque, 2009). 
Other papers have used both husband's education and wife's education as measures of quality. We do not use this approach here, as the relationship between education and occupation make it difficult to separate out education from same-occupation matching.

\section{A. Empirical Predictions}

The comparison of the preferences and search costs explanations focuses on the difference in average wage for same-occupation husbands versus different-occupation husbands, calculated across women in the same occupation.

In the preferences mechanism, the difference in husband's wage between sameoccupation husbands and different-occupation husbands should be the most negative when men are scarce in the wife's occupation (percent male is low), and the difference should be less negative in occupations where men are more plentiful.

In the search cost mechanism, the difference in husband's wage between sameoccupation husbands and different-occupation husbands should be the most negative when men are plentiful in the wife's occupation (percent male is high). The search cost differential between within-occupation search and outside-occupation search should be greatest when percent male is high.

This suggests a differences-in-differences approach. The first difference is the difference in husband's wage between women, of the same occupation, who match with same-occupation husbands versus different-occupation husbands. The second difference is to compare this gap across occupations that have a high percent male versus a low percent male.

Our approach differs substantially from the small existing literature that provides empirical evidence on the relative importance of preferences and search frictions in generating similarities in traits between husbands and wives. Belot and Francesconi (2013) provide the most direct evidence using British speed-dating data which allows them to observe dating 
choices under different choice sets. They find that meeting opportunities play a substantial role in determining the characteristics of the individuals chosen for dating proposals. They find no evidence of preferences for occupational similarity using a very course three category measure of occupation. $^{8}$ Nielsen and Svarer (2009) use Danish data to investigate educational homogamy of married couples. They find that about half of marital sorting on education is explained by individuals marrying spouses who attended the same or nearby educational institutions. They interpret this as evidence of low search frictions in the marriage markets of educational institutions. They also find that the density of women in a man's education group in the municipality of education positively predicts sorting.

Hitsch, Hortacsu and Ariely (2010) use data from an online dating website to estimate preferences based on which potential partners are contacted. These preferences estimates are to predict matches using the Gale-Shapley matching algorithm. Comparing matches predicted by their algorithm to data on married couples, they find that they predict well sorting by age, appearance and income, but underpredict the degree of sorting by education and race/ethnicity. Because Gale-Shapley assumes a frictionless matching environment, they conclude that preferences alone can predict the degree of sorting on some characteristics, but that search frictions may play a role in determining the degree of sorting by education and race/ethnicity.

Wong (2003) investigates the low rate of the intermarriage rate between black men and white women by estimating a structural model that allows for a "mating taboo." She finds that the taboo, or preferences, explains the majority of the shortfall in this form of intermarriage. Her model, however, assumes random matching, so does not explicitly consider whether the low

\footnotetext{
${ }^{8}$ The three categories are professional and managerial, skilled nonmanual, and other occupations.
} 
intermarriage rate in part reflects the fact that black men are more likely to meet black women than white women. ${ }^{9}$

Ours is the first study to investigate same-occupation matching, and the first study to propose a direct test for search frictions using marital, rather than dating, matches.

\section{B. Differences-in-Differences Approach}

Our Differences-in-Differences approach is implemented with the following specification:

$$
\begin{aligned}
\text { HusbandWage }_{i j k} & =\beta_{o}+\beta_{1} \text { Same_Occ }_{i}+\beta_{2} \text { Same_Occ }_{i} * \% \text { Male }_{j}+X_{i} \beta_{3} \\
& +\sum_{m=1}^{4} \theta_{m} * \text { Same }_{-} \text {Occ }_{i} * \text { Occ }_{-} \text {WageVar }_{m j}+\sum_{j=1}^{J} \lambda_{j} * \text { Occ }_{j}+\sum_{k=1}^{K} \phi_{k} * \text { Occ }_{k} \\
& +\sum_{s=1}^{S} \delta_{s} * \text { State }_{i}+\sum_{s=1}^{S} \gamma_{s} * \text { State }_{i} * \text { Urban }_{i}+\varepsilon_{i j k}
\end{aligned}
$$

For couple $i$ with wife's occupation $j$ and husband's occupation $k$, Husb_Wage is husband's calculated hourly wage. ${ }^{10}$ Same_Occ remains an indicator that equals 1 if husband and wife share the same occupation. \% Male $_{j}$ remains percent male in wife’s occupation. Occ_WageVar 1 -Occ_WageVar 4 is a set of four occupation-level wage characteristics for occupation $j$ : the average male wage, the average female wage, the male wage variance and the female wage variance. $X$ is the vector of controls for husband's and wife's characteristics used in equation (1). The model also contains fixed-effects for wife's occupation, husband's occupation, state and state interacted with urban status. Standard errors are corrected for clustering by wife’s occupation.

\footnotetext{
${ }^{9}$ Wong does consider the role of what she terms “courtship opportunities," but this refers to the quality distributions for black women and white women. If she gives black women the quality distribution of white women or white women the quality distribution of black women, both cases reduce the intermarriage rate.

${ }^{10}$ Hourly wage is calculated by dividing annual earnings by annual hours. Annual hours are calculated by multiplying weeks worked last year times usual hours per week. Starting in 2008, the ACS reports weeks of work in intervals. We impute actual weeks of work using individuals from the 2004-2007 ACS of the same education and gender reporting weeks of work in the same interval.
} 
If same-occupation matching is predominantly driven by preferences for sameoccupation spouses, the prediction is that the coefficient on Same_Occ*\%Male is positive. The difference in wages between same-occupation husbands and different-occupation husbands should grow less negative as men become more plentiful in the occupation.

If same-occupation matching is predominantly driven by search costs, the prediction is that the coefficient on Same_Occ*\%Male is negative. The difference in wages between sameoccupation husbands and different-occupation husbands should become more negative as the search costs within occupation become lower.

Percent male in the occupation is correlated with the wage distribution and gender wage gap in the occupation. Occupation fixed-effects control for the main effects of occupation-level wage characteristics, but we also include interactions of Same_Occ with occupation-level wage characteristics.

The specification includes occupation fixed-effects for both wife's occupation and husband's occupation. Wife's occupation fixed-effects are necessary because we are comparing the difference in wages between same-occupation husbands and different-occupation husbands across wives in the same occupation. Husband's occupation fixed-effects are included to control for the overall attractiveness of men in any given occupation so that we can isolate the effects of a same-occupation match. For example, we want to control for the fact that male doctors and lawyers are generally considered attractive husbands, and conditional on that, estimate whether male doctors and lawyers are particularly attractive to women who share their occupation.

The preferences and search cost mechanisms also generate some predictions for the main effects of Same_Occ and \%Male, but these main effects are more susceptible to omitted variable bias than the interaction term. For example, the search cost mechanism predicts that the main effect of \%Male should be positive, that women in occupations with a higher male percentage 
(lower search costs) should have higher-quality husbands. But the main effect of percent male is not estimated, due to the inclusion of wife's occupation fixed effects. Furthermore, a comparison of husband's wages across wives in different occupations would be rather suspect. The preferences mechanism predicts that the main effect of Same_Occ is negative, that women take lower earning husbands in order to match within occupation. But it could be that women who match within occupation are different in unobserved ways from those who do not. For example, perhaps women who work more hours are more likely to match within occupation.

The coefficient on the interaction term provides a much more compelling test between the two mechanisms, as it is much less likely that omitted variable bias affects the differences-indifferences estimate. For the interaction term to be biased, there would have to be an omitted variable that not only affects the gap in husband's wages between women within the same occupation who match with same-occupation husbands versus different-occupation husbands, but also causes that gap to be correlated with sex-composition of the occupation.

A key concern in equation (2) is that in order to have the desired interpretation, the specification must include adequate controls for wife’s quality. As already discussed, unobserved characteristics will more likely bias the main effect of Same_Occ than the interaction term. It would still be preferable to control for woman's quality in more detail than the current controls for education, age, location and occupation. To that end, we consider an alternative specification for equation (2) that uses the relative wages of husband and wife as the outcome variable. In other words, the dependent variable measures the extent to which the woman is marrying up or down in terms of wage. 
(3)

$$
\begin{aligned}
&(\text { HusbandWage /WifeWage })_{i j k}= \beta_{o}+\beta_{1} \text { Same }_{-} \text {Occ }_{i}+\beta_{2} \text { Same_Occ }_{i} * \% \text { Male }_{j}+X_{i} \beta_{3} \\
&+\sum_{m=1}^{4} \theta_{m} * \text { Same_Occ }_{i} * \text { Occ_WageVar } \\
& m j
\end{aligned}
$$

An additional benefit of the specification in equation (3) is that it is symmetric between husbands and wives. ${ }^{11}$ This specification could, therefore, just as easily be interpreted as estimating changes in the wife's relative quality for same-occupation matches relative to different-occupation matches as women become less plentiful in husband's occupation. There remain, however, the caveats discussed earlier that a wife's wage could be endogenous to her marriage market match and that wife’s wage is not necessarily as strong a proxy for partner quality as husband's wage.

\section{Interaction Effects with Workplace Communication}

The search cost mechanism should be most relevant in occupations in which there is sufficient workplace interaction with co-workers to facilitate marital search. To test whether this is true, we obtained a measure of communication with co-workers from the $\mathrm{O} * \mathrm{Net}$ database (version 18), containing a rich set of occupational characteristics describing the different combinations of skills, abilities, and work contexts required in each occupation $(\mathrm{O} *$ Net Research Center). Specifically, the workplace communication index is obtained from the "Generalized Work Activities” descriptors and it measures the extent of “Communicating with Supervisors, Peers, or Subordinates: Providing information to supervisors, co-workers, and subordinates by

\footnotetext{
${ }^{11}$ Because the interaction term is zero unless husband and wife share the same occupation, it is equivalent to the interaction of Same_Occ with the percent male in husband's occupation.
} 
telephone, in written form, e-mail, or in person” on a scale from 0 to $7 .^{12}$ Interactions with this occupation-level measure of workplace communication are added to equation (2):

$$
\begin{aligned}
\text { HusbandWage }_{i j k} & =\beta_{o}+\beta_{1} \text { Same }_{-} \text {Occ }_{i}+\beta_{2} \text { Same_Occ }_{i} * \% \text { Male }_{j} \\
& +\beta_{3} \text { Same_Occ }_{i} * \text { WorkplaceComm }_{j}+\beta_{4} \text { Same_Occ }_{i} * \% \text { Male }_{j} * \text { WorkplaceComm }_{j} \\
& +X_{i} \beta_{5}+\sum_{m=1}^{4} \theta_{m} * \text { Same_Occ }_{i} * O c \text { OC_WageVar }_{m}+\sum_{j=1}^{J} \lambda_{j} * \text { Occ }_{j}+\sum_{k=1}^{K} \phi_{k} * \text { Occ }_{k} \\
& +\sum_{s=1}^{S} \delta_{s} * \text { State }_{i}+\sum_{s=1}^{S} \gamma_{s} * \text { State }_{i} * \text { Urban }_{i}+\varepsilon_{i j k}
\end{aligned}
$$

In equation (4), the $\beta_{2}$ coefficient estimates the coefficient on Same_Occ*\%Male for occupations with very limited interaction with coworkers. In these occupations, we would expect same-occupation matches to be driven by preferences as opposed to search costs. A positive estimate for $\beta_{2}$ would be consistent with this prediction.

The estimates of $\beta_{4}$ indicates how the coefficient on Same_Occ*\%Male changes when estimated for workers in occupations with higher levels of workplace interaction. If the search cost mechanism becomes more relevant in occupations with higher levels of workplace interaction, then we would expect to obtain a negative estimate for $\beta_{4}$.

\section{Results}

Panel A of Table 3 reports the estimates from equations (2) and (3) for the full sample. ${ }^{13}$

\footnotetext{
${ }^{12}$ These scores are collected from workers and occupational experts using questionnaires assessing the importance of different occupational requirements. There are other measures of interpersonal contact available in the ONET data, but this is the only one that is specific to co-workers, who are more likely to be in the same occupation. There is, for example, a measure of face-to-face contact, but it is not restricted to co-workers, and will include clients and others less likely to be from the same occupation. If the face-to-face measure is used in place of our preferred workplace communication measure, the estimates display a very similar pattern, but without statistical significance. ${ }^{13}$ The samples in Tables 3 and 4 are the same as used in Tables 2, with the additional restriction that observations are dropped if husband's wage or wife's wage is less than 1 and greater than 500. If non-working wives are included in the sample in Table 4, the coefficients on Same_Occ*\%Male become slightly more negative (more supportive of search cost mechanism). This is not surprising, given that any preferences for same-occupation spouses should be weaker for wives less attached to the labor market.
} 
Results are reported using both the linear and logged version of the husband's wage and wage ratio. The coefficient on the Same_Occ*\%Male interaction is negative for all four dependent variables and statistically significant for all but the linear wage ratio.

In panels B and C, the sample is again split into wives with and without college degrees. The coefficients lose significance in most cases when the sample is divided, but the basic pattern of negative interaction terms (with similar magnitudes) remains. The negative coefficient estimates for the Same_Occ*\%Male interaction are consistent with a search costs, rather than preferences, explanation for same-occupation matches.

Table 4 adds the interactions with occupation-level measures of workplace communication described in equation (4). The workplace communication index is not available for 72 of the 333 occupation categories, generating a roughly 30\% loss of sample. Column 1 reports the results when husband's wage is the dependent variable. As predicted the coefficient on Same_Occ*\%Male is positive, indicating that when workplace communication is very low, the coefficient on the interaction term is more consistent with a preferences explanation for same-occupation matching. Also as predicted, the coefficient on the triple interaction, Same_Occ*\%Male*WorkplaceComm, is negative and significant, indicating that as the level of workplace communication increases, there is greater support for the search cost explanation for same-occupation matching. The total effect of Same_Occ*\%Male becomes negative once the WorkplaceComm index is greater than 3.75 (about the $20^{\text {th }}$ percentile of our analysis sample).

In column 2, the dependent variable is logged husband's wage. The coefficient estimates are statistically insignificant, but display the same pattern as that in column 1 . The crossing point of WorkplaceComm (where the effect of Same_Occ*\%Male switches from positive to negative) is very similar to that for column 1 . In column 3 , the results for the wage ratio display the same pattern and are statistically significant. The crossing point is 4.62 , roughly the median 
of our sample. The only outcome variable that does not generate the predicted pattern of results is the logged wage ratio in column 4.

Overall, the results in Table 4 suggest that same-occupation matching in occupations with very limited workplace interaction is consistent with a preferences mechanism. However, for occupations with sufficient workplace interaction, the results indicate that the search cost mechanism dominates the preferences mechanism as an explanation for same-occupation matches. Our estimates of the coefficient on Same_Occ*\%Male reported in Tables 3 should therefore be thought of as the interaction effect averaged across occupations with higher and lower levels of workplace communication.

Finally, in Table 5, we consider matching on field of bachelor's degree, rather than matching on occupation. Field of degree is available in the ACS starting in 2009 for all individuals reporting completing a bachelor's degree. The advantage of using field of degree is that we avoid the concerns that current occupation differs from occupation at time of matching, or that current occupation is endogenous to partner characteristics. The disadvantages of using field of degree are that our analysis is limited to couples in which both spouses have a bachelor's degree and that we do not have information by field of degree analogous to the workplace communication index used in Table 6. The ACS provides detailed field of degree codes for 181 fields. $8.7 \%$ of the sample is matched on field of degree using the 181 detailed categories. ${ }^{14}$

Table 5 reports results from equations (2) and (3) in which the indicator for same occupation is replaced with an indicator for same field of degree, percent male and average wage in occupation are replaced by analogous measures calculated by field of degree. Consistent with previous results, the coefficients on the Same_Field*\%Male interactions are negative for all husband's wage and wage ratio outcomes. Comparing these results to those for college-educated

\footnotetext{
${ }^{14}$ Using the 38 general field of degree categories, $17.1 \%$ of college-educated couples in our sample are matched on field of degree.
} 
women in Table 3, the magnitudes on the interaction terms are larger using field of degree compared to occupation. Like the results for college-educated women in Table 3, the coefficients are largely statistically insignificant.

\section{Conclusions}

The results in this paper demonstrate that there is considerable within-occupation marital matching and that within-occupation matching is highly responsive to the sex-composition of the occupation.

The analysis of husband's wage and wage ratio with wife generates empirical results that are more consistent with a search cost explanation than a preferences explanation for the prevalence of same-occupation matches. Additional analysis using information on the extent of workplace communication confirms that the results are most consistent with a search cost explanation when there is a sufficient workplace interaction to facilitate marital search.

There is a growing literature that indicates the potential importance of schools and workplaces as local marriage markets. Previous research has found that workplace sex composition affects divorce rates (McKinnish, 2007; Svarer 2007). Kaufman, Messner and Solis (2013) use regression discontinuity analysis to document the large marriage market return for women to attending an elite university. Mansour and McKinnish (2014) find that individuals with large marital age gaps tend to be lower quality in terms of cognitive ability, educational attainment, earnings and appearance. Their explanation is that high-skilled individuals interact more heavily with similarly-aged peers in school and workplace while low-skilled individuals spend more time in age-heterogeneous settings.

The implication that individuals often match within occupation because it is simply easier to meet potential partners who share their occupation (whether through schooling or workplace), rather than because of preferences, suggests that marriage markets are much more local than 
typically modeled by economists. As a result, choices about where to work or where to go to school can have important consequences for matching by changing the group of people with whom one interacts most easily. In marriage models with frictionless matching, characteristics such as education and occupational wage have traditionally affected matching through the marital surplus. Our findings suggest they also affect matching by changing the set of prospective mates with whom one interacts at lowest cost. 


\section{References}

Abramitzky, Ran, Adeline Delavande and Luis Vasconcelos. 2011. "Marrying Up: the Role Of Sex Ratio in Assortative Matching.” American Economic Journal: Applied Economics 3(3):124-56.

Angrist, Josh. 2002. "How do sex ratios affect marriage and labor markets? Evidence from America’s second generation.” Quarterly Journal of Economics. 117(3) 997-1038.

Belot, Michele and Marco Francesconi. 2013. "Dating Preferences and Meeting Opportunities in Mate Choice Decisions.” Journal of Human Resources 48(2):474-508.

Bloch, Francis and Harl Ryder. 2000. “Two-Sided Search, Marriage and Matchmakers.” International Economic Review 41(1):93-115

Burdett, Ken and Melvyn Coles. 1997. "Marriage and Class.” Quarterly Journal of Economics 112(1): 141-68.

Cameron, C.A., J.B Gelbach and D.L. Miller. 2011. "Robust Inference with Multi-way Clustering.” Journal of Business and Economic Statistics 29(2) 238-49.

Charles, Kerwin and Ming Luoh. 2010. "Male Incarceration, the Marriage Market, and Female Outcomes.” Review of Economics and Statistics 92(3):614-27.

Chiappori, Pierre-Andre, Bernard Fortin, Guy Lacroix. 2002. “Marriage Markets, Divorce ‘ Legislation and Household Labor Supply” Journal of Political Economy 110(1) 37-72.

Chiappori, Pierre-Andre, Sonia Oreffice and Climent Quintana-Domeque. 2010. "Matching with a Handicap: The Case of Smoking in the Marriage Market.” IZA Discussion Paper \#5392.

Chiappori, Pierre-Andre, Sonia Oreffice and Climent Quintana-Domeque. Forthcoming . "Fatter Attraction: Anthropometric and Socioeconomic Characteristics in the Marriage Market” Journal of Political Economy.

Choo, Eugene and Aloysius Siow. 2006. "Who Marries Whom and Why” Journal of Political Economy. 114(1): 175-201.

Fisman, Raymond, Sheena Iyengar, Emir Kamenica, and Itamar Simonson. 2006. “Gender Differences in Mate Selection: Evidence from a Speed Dating Experiment." Quarterly Journal of Economics 121(2): 673-97.

Hitsch, Guner, Ali Hortascsu and Dan Ariely. 2010. "Matching and Sorting in Online Dating” American Economic Review 100(1): 130-63.

Hout, Michael. 1982 “The Association Between Husbands’ and Wives’ Occupations in 
Two-Earner Families.”American Journal of Sociology 87 (September): 397-409.

Jacquet, Nicholas and Serene Tan. 2007. "On the Segmentation of Markets.” Journal of Political Economy 115(4) 639:64.

Kalmijn, Matthijs. 1994. "Assortative Mating by cultural and economic occupational status” American Journal of Sociology 100:422-52.

Kalmijn, Matthijs. 1998. "Intermarriage and Homogamy: Causes, Patterns, Trends.” American Review of Sociology 24: 395-421.

Kaufman, Katja, Matthias Messner and Alex Solis. 2013. "Returns to Elite Higher Education in the Marriage Market: Evidence from Chile” Bocconi University Working Paper \#489.

Lafortune, Jeanne. 2013. "Making Yourself Attractive: Pre-Marital Investments and Returns to Education in the Marriage Market." American Economic Journal: Applied Economics 5(2):151-78.

Mansour, Hani and Terra McKinnish. 2014. "Who Marries Differently-Aged Spouses? Ability, Education, Occupation, Earnings and Appearance” Review of Economics and Statistics. 96(3) 577-80.

McKinnish, Terra. 2007. "Sexually-Integrated Workplaces and Divorce: Another Form of Onthe-Job Search,” Journal of Human Resources, 42(2): 331-352.

Moen, Espen. 1997 “Competitive Search Equilibrium.” Journal of Political Economy 105(2):385-411.

Nielsen, Helena and Michael Svarer. 2009. "Educational Homogamy: How Much is Opportunity?” Journal of Human Resources 44(4): 1066-86.

Oreffice, Sonia and Climent Quintana-Domeque. 2009. "Anthropometry and socioeconomics in ‘ the couple: evidence from the PSID.” FEDEA wp\#2009-22.

Smith, Lones. 2006. "The Marriage Model with Search Frictions,” Journal of Political Economy, Vol. 114(6):1124-1144.

Svarer, Michael. 2007. "Working Late: Do Workplace Sex Ratios Affect Partnership Formation and Dissolution?” Journal of Human Resources 42(3) 583-595.

Weitzman, Martin. 1979. “Optimal Search for the Best Alternative.” Econometrica 47(3):641-54.

Wong, Linda. 2003. “Why do only 5.5\% of black men marry white women?” International Economic Review 44(3) 803-26. 
Table 1: Fraction Female and Same-Occupation Matching by Occupation Category

\begin{tabular}{|c|c|c|c|c|}
\hline Occupation & $\begin{array}{l}\text { Sample } \\
\text { size }\end{array}$ & Female $^{(\mathrm{a})}$ & $\begin{array}{l}\text { \% Married Females } \\
\text { w/ same occupation } \\
\text { husbands }{ }^{(b)}\end{array}$ & $\begin{array}{l}\% \text { Married Males } \\
\text { w/ same occupation } \\
\text { wives }^{(b)}\end{array}$ \\
\hline Vehicle/Mobile Equipment Mechanics & 72,021 & 0.02 & 0.19 & 0.00 \\
\hline Extractive Occupations & 6,969 & 0.02 & 0.30 & 0.00 \\
\hline Material Moving Equipment Operators & 18,389 & 0.03 & 0.11 & 0.00 \\
\hline Construction Trades, Except Supervisors & 160,570 & 0.03 & 0.36 & 0.01 \\
\hline Supervisors, Construction Occupations & 31,560 & 0.03 & 0.10 & 0.00 \\
\hline Helpers, Construction and Extractive & 64,338 & 0.04 & 0.19 & 0.01 \\
\hline Fire fighting and Fire Prevention & 12,624 & 0.05 & 0.35 & 0.02 \\
\hline Water Transportation Occupations & 2,252 & 0.05 & 0.08 & 0.00 \\
\hline Plant and System Operators & 8,520 & 0.05 & 0.06 & 0.00 \\
\hline Precision Metal Working Occupations & 15,484 & 0.06 & 0.12 & 0.01 \\
\hline Miscellaneous Mechanics and Repairers & 30,498 & 0.06 & 0.06 & 0.00 \\
\hline Rail Transportation Occupations & 3,558 & 0.07 & 0.53 & 0.03 \\
\hline Fishers, Hunters, and Trappers & 1,606 & 0.07 & 0.40 & 0.02 \\
\hline Electrical/Electronic Equip. Repairers & 35,006 & 0.07 & 0.13 & 0.01 \\
\hline Supervisors of mechanics and repairers & 9,191 & 0.08 & 0.05 & 0.00 \\
\hline Forestry and Logging Occupations & 5,787 & 0.09 & 0.09 & 0.01 \\
\hline Precision Woodworking Occupations & 2,644 & 0.10 & 0.04 & 0.01 \\
\hline Motor Vehicle Operators & 147,641 & 0.13 & 0.27 & 0.03 \\
\hline Military & 35,831 & 0.14 & 0.53 & 0.09 \\
\hline Engineers & 57,214 & 0.15 & 0.29 & 0.06 \\
\hline Farm Operators and Managers & 22,582 & 0.17 & 0.38 & 0.06 \\
\hline Metal/Plastic Processing Machine Operators & 2,445 & 0.18 & 0.03 & 0.01 \\
\hline Metal/Plastic Working Machine Operators & 6,125 & 0.18 & 0.06 & 0.01 \\
\hline Related Agricultural Occupations & 51,567 & 0.18 & 0.12 & 0.03 \\
\hline Production supervisors or foremen & 30,832 & 0.20 & 0.07 & 0.02 \\
\hline Police and Detectives & 51,202 & 0.22 & 0.40 & 0.09 \\
\hline Woodworking Machine Operators & 16,130 & 0.23 & 0.13 & 0.04 \\
\hline Printing Machine Operators & 8,235 & 0.26 & 0.08 & 0.03 \\
\hline Engineering /Technologists and Technicians & 30,662 & 0.26 & 0.06 & 0.02 \\
\hline Freight, Stock, and Material Handlers & 96,667 & 0.27 & 0.12 & 0.04 \\
\hline Farm Occupations, Except Managerial & 27,906 & 0.27 & 0.29 & 0.13 \\
\hline Supervisors of guards & 2,561 & 0.29 & 0.07 & 0.02 \\
\hline Fabricators, Assemblers, and Hand Working & 59,668 & 0.29 & 0.17 & 0.06 \\
\hline Guards & 29,657 & 0.31 & 0.09 & 0.03 \\
\hline Machine Operators, Assorted Materials & 70,146 & 0.32 & 0.13 & 0.05 \\
\hline Architects & 5,967 & 0.32 & 0.13 & 0.08 \\
\hline Mathematical and Computer Scientists & 75,328 & 0.32 & 0.13 & 0.05 \\
\hline Cleaning/Building Service, Except Households & 79,465 & 0.34 & 0.12 & 0.05 \\
\hline Science Technicians & 2,882 & 0.35 & 0.03 & 0.02 \\
\hline
\end{tabular}




\begin{tabular}{|c|c|c|c|c|}
\hline Technicians, Except Health/Engineering/Science & 77,440 & 0.37 & 0.16 & 0.09 \\
\hline Mail and Message Distributing Occupations & 26,014 & 0.39 & 0.12 & 0.06 \\
\hline Health Diagnosing Occupations & 36,483 & 0.41 & 0.27 & 0.24 \\
\hline Lawyers and Judges & 32,710 & 0.42 & 0.25 & 0.21 \\
\hline Production Inspectors/Testers/Samplers/Weighers & 24,627 & 0.42 & 0.04 & 0.02 \\
\hline Material Recording/Scheduling/Distributing Clerks & 91,267 & 0.42 & 0.06 & 0.04 \\
\hline Natural Scientists & 22,420 & 0.43 & 0.17 & 0.14 \\
\hline Executive, Administrative, and Managerial & 417,549 & 0.43 & 0.20 & 0.17 \\
\hline Supervisors and proprietors of sales jobs & 133,441 & 0.43 & 0.11 & 0.08 \\
\hline Precision Food Production Occupations & 15,820 & 0.44 & 0.08 & 0.06 \\
\hline Sales Reps, Finance and Business Services & 58,690 & 0.50 & 0.09 & 0.08 \\
\hline Computer and peripheral equipment operators & 4,053 & 0.51 & 0.03 & 0.03 \\
\hline Writers, Artists, Entertainers, and Athletes & 80,602 & 0.51 & 0.13 & 0.14 \\
\hline Teachers, Postsecondary & 41,408 & 0.53 & 0.21 & 0.23 \\
\hline Sales Representatives, Commodities & 265,042 & 0.56 & 0.09 & 0.11 \\
\hline Duplicating/Mail/Other Office Machine Operators & 3,758 & 0.57 & 0.04 & 0.05 \\
\hline Precision Textile, Apparel, and Furnishings Machine & 3,517 & 0.57 & 0.02 & 0.02 \\
\hline Management Related Occupations & 195,372 & 0.59 & 0.11 & 0.15 \\
\hline Food Preparation and Service Occupations & 201,458 & 0.59 & 0.12 & 0.21 \\
\hline Social Scientists and Urban Planners & 15,505 & 0.62 & 0.05 & 0.09 \\
\hline Social, Recreation, and Religious Workers & 52,580 & 0.64 & 0.05 & 0.12 \\
\hline Office supervisors & 47,407 & 0.66 & 0.02 & 0.03 \\
\hline Textile, Apparel, and Furnishings Machine & 16,285 & 0.68 & 0.06 & 0.11 \\
\hline Adjusters and Investigators & 102,032 & 0.72 & 0.05 & 0.13 \\
\hline Precision Workers, Assorted Mate & 23,012 & 0.74 & 0.02 & 0.07 \\
\hline Sales demonstrators / promoters / models & 1,609 & 0.74 & 0.02 & 0.10 \\
\hline Health Technologists and Technicians & 64,998 & 0.78 & 0.04 & 0.13 \\
\hline Communications Equipment Operators & 2,837 & 0.78 & 0.01 & 0.03 \\
\hline Records Processing Occupations, Except Financial & 24,495 & 0.78 & 0.01 & 0.05 \\
\hline Therapists & 30,751 & 0.80 & 0.05 & 0.20 \\
\hline Librarians, Archivists, and Curators & 6,582 & 0.80 & 0.02 & 0.06 \\
\hline Teachers, Except Postsecondary & 267,587 & 0.80 & 0.11 & 0.38 \\
\hline Personal Service Occupations & 119,831 & 0.81 & 0.03 & 0.17 \\
\hline Miscellaneous Administrative Support Occupations & 85,477 & 0.83 & 0.01 & 0.07 \\
\hline Information Clerks & 52,332 & 0.85 & 0.01 & 0.07 \\
\hline Health Assessment and Treating Occupations & 104,270 & 0.89 & 0.05 & 0.35 \\
\hline Health Service Occupations & 131,585 & 0.89 & 0.03 & 0.21 \\
\hline Financial Records Processing Occupations & 66,664 & 0.90 & 0.01 & 0.04 \\
\hline Private Household Occupations & 45,295 & 0.90 & 0.03 & 0.31 \\
\hline Secretaries, Stenographers, and Typists & 130,640 & 0.96 & 0.00 & 0.10 \\
\hline
\end{tabular}

(a) Sample of men and women aged 22-55 who reported an occupation in the 2008-2001 ACS.

(b) Sample of married women (or men) aged 22-55 who reported an occupation in the 2008-2001 ACS. 
Table 2: Occupation matching by occupation sex composition

\begin{tabular}{llll}
\hline & Full Sample & $\begin{array}{l}\text { Wives with } \\
\text { College }\end{array}$ & $\begin{array}{l}\text { Wives w/o } \\
\text { College }\end{array}$ \\
\hline \% Male in wife's occupation & $\begin{array}{l}0.159^{* * *} \\
(0.029)\end{array}$ & $\begin{array}{l}0.165^{* * *} \\
(0.041)\end{array}$ & $\begin{array}{l}0.152^{* * *} \\
(0.023)\end{array}$ \\
\% Female in husband's occupation & $\begin{array}{l}0.074^{* *} \\
(0.030)\end{array}$ & $\begin{array}{l}0.060 \\
(0.039)\end{array}$ & $\begin{array}{l}0.125^{* * *} \\
(0.009)\end{array}$ \\
Male share in wife's occupation & 0.760 & 0.740 & $0.860^{* * *}$ \\
& $(0.679)$ & $(0.762)$ & $(0.330)$ \\
Female share in husband's occupation & $2.24 * * *$ & $2.65^{* * *}$ & 0.456 \\
& $(0.578)$ & $(0.649)$ & $(0.431)$ \\
$\mathrm{N}$ & 83,792 & 50,161 & 33,631 \\
\hline
\end{tabular}

Notes: Sample of married couples in the 2008-2011 ACS in their first marriage, married less than 5 years, between ages of 22 and 45, with a white native-born wife. Dependent variable equals 1 if couple shares same occupation. Table reports results from equation (1). Standard errors (in parentheses) 2-way clustered by wife's occupation and husband's occupation using Cameron, Gelbach and Miller (2011). *** $\mathrm{p}<0.01,{ }^{* *} \mathrm{p}<0.05,{ }^{*} \mathrm{p}<0.1$ 
Table 3: Husband's wage by occupation matching with wife

\begin{tabular}{|c|c|c|c|c|}
\hline & $\begin{array}{l}\text { Husband's } \\
\text { Wage }\end{array}$ & $\begin{array}{l}\text { Log(Husb’s } \\
\text { Wage) }\end{array}$ & $\begin{array}{l}\text { Husb’s Wage/ } \\
\text { Wife's Wage }\end{array}$ & $\begin{array}{l}\text { Log Wage } \\
\text { Ratio }\end{array}$ \\
\hline \multicolumn{5}{|l|}{ A. Full Sample } \\
\hline $\begin{array}{l}\text { Same occupation * \% Male in } \\
\text { occupation }\end{array}$ & $\begin{array}{l}-2.70 * * \\
(1.10)\end{array}$ & $\begin{array}{l}-0.071^{*} \\
(0.038)\end{array}$ & $\begin{array}{l}-0.178 \\
(0.144)\end{array}$ & $\begin{array}{l}-0.094 * * \\
(0.041)\end{array}$ \\
\hline $\mathrm{N}$ & 62,636 & 62,636 & 62,636 & 62,636 \\
\hline \multicolumn{5}{|l|}{ B. Wives with College } \\
\hline $\begin{array}{l}\text { Same occupation * \% Male in } \\
\text { occupation }\end{array}$ & $\begin{array}{l}-2.24^{*} \\
(1.25)\end{array}$ & $\begin{array}{r}-0.030 \\
(0.053)\end{array}$ & $\begin{array}{l}-0.040 \\
(0.178)\end{array}$ & $\begin{array}{l}-0.030 \\
(0.045)\end{array}$ \\
\hline $\mathrm{N}$ & 40,339 & 40,339 & 40,339 & 40,339 \\
\hline \multicolumn{5}{|l|}{ C. Wives w/o College } \\
\hline $\begin{array}{l}\text { Same occupation * \% Male in } \\
\text { occupation }\end{array}$ & $\begin{array}{l}-3.12 \\
(2.99)\end{array}$ & $\begin{array}{l}-0.081 \\
(0.074)\end{array}$ & $\begin{array}{l}-0.229 \\
(0.255)\end{array}$ & $\begin{array}{l}-0.130 \\
(0.092)\end{array}$ \\
\hline $\mathrm{N}$ & 22,297 & 22,297 & 22,297 & 22,297 \\
\hline
\end{tabular}

Notes: Sample described in notes of Tables 2. Observations excluded if husband's or wife's wage is less than 1 or greater than 500. Table reports estimates from equation (2).

Standard errors (in parentheses) clustered by wife's occupation. ${ }^{* * *} \mathrm{p}<0.01,{ }^{* *} \mathrm{p}<0.05,{ }^{*} \mathrm{p}<0.1$ 
Table 4: Interaction with Workplace Communication

\begin{tabular}{lcccc}
\hline & $\begin{array}{c}(1) \\
\text { Husband’s } \\
\text { Wage }\end{array}$ & $\begin{array}{c}\text { Log(Husb’s } \\
\text { Wage) }\end{array}$ & $\begin{array}{c}(3) \\
\text { Wage Ratio }\end{array}$ & $\begin{array}{c}(4) \\
\text { Log(Wage } \\
\text { Ratio) }\end{array}$ \\
\hline Same occupation * \% Male & $\begin{array}{c}20.43^{* *} \\
(8.03)\end{array}$ & 0.372 & $1.92^{*}$ & -0.153 \\
& $(0.354)$ & $(1.09)$ & $(0.393)$ \\
Same occupation * \% Male * & $-5.45^{* * *}$ & -0.111 & $-0.416^{*}$ & 0.007 \\
Workplace communication & $(1.91)$ & $(0.077)$ & $(0.239)$ & $(0.086)$ \\
$\mathrm{N}$ & 44,038 & 44,038 & 44,038 & 44,038 \\
\hline
\end{tabular}

Notes: Sample described in notes of Tables 2. Table reports estimates from equation (3). Workplace communication is an occupation-level index ranging from 0 to 7 measuring degree of communication with supervisors, co-workers and supervisors. Standard errors (in parentheses) clustered by wife's occupation. *** $\mathrm{p}<0.01$, ** $\mathrm{p}<0.05, * \mathrm{p}<0.1$ 
Table 5: Husband's Wage by Matching on Field of Degree, College-Educated Couples

\begin{tabular}{lcccc}
\hline & $\begin{array}{c}(1) \\
\text { Husband’s } \\
\text { Wage }\end{array}$ & $\begin{array}{c}(2) \\
\text { Log (Husb’s } \\
\text { Wage) }\end{array}$ & $\begin{array}{c}(3) \\
\text { Wage Ratio }\end{array}$ & $\begin{array}{c}(4) \\
\text { Log(Wage } \\
\text { Ratio) }\end{array}$ \\
\hline Same Field of Degree & $\begin{array}{c}6.89 * * * \\
(2.26)\end{array}$ & $\begin{array}{c}0.151^{* * *} \\
(0.058)\end{array}$ & 0.237 & 0.160 \\
& -2.48 & -0.012 & -0.300 & $-0.193^{*}$ \\
Same Field of Degree * & $(2.62)$ & $(0.076)$ & $(0.190)$ & $(0.096)$ \\
\% Male in Field of Degree & & & & \\
$\mathrm{N}$ & 20,641 & 20,641 & 20,641 & 20,641 \\
\hline
\end{tabular}

Notes: Sample contains only couples in which both husband and wife have college degrees. Field of degree is not available prior to 2009. Table reports estimates from equation (2), replacing the indicator for same occupation with an indicator for same field of degree, and replacing percent male and wage characteristics of occupation with measures for field of degree. Standard errors (in parentheses) clustered by wife's field of degree. ${ }^{* * *} \mathrm{p}<0.01,{ }^{* *} \mathrm{p}<0.05$, * $\mathrm{p}<0.1$ 